\title{
PREDICTION OF ULTRALOW CYCLE FATIGUE DAMAGE OF THIN-WALLED STEEL BRIDGE PIERS
}

\author{
Zhan-Zhan Tang ${ }^{1,2}$, Han-Yang Xue ${ }^{1}$, Hong Liu ${ }^{4}$ and Wei Zhang ${ }^{*}, 2,3$ \\ 'College of Civil Science and Engineering, Yangzhou University, Yangzhou, Jiangsu 225127, China \\ ${ }^{2}$ School of Civil Engineering, Fujian University of Technology, Fuzhou 350118, China \\ ${ }^{3}$ Institute of Theoretical and Applied Mechanics of the Czech Academy of Sciences, Prague 190 00, Czech Republic \\ ${ }^{4}$ Faculty of Civil Engineering, Department of Structures, VSB-Technical University of Ostrava, L. Podéšté 1875, 70833 Ostrava, Poruba, Czech Republic \\ *(Corresponding author: E-mail: zhangwei621@gmail.com)
}

\section{A B S T R A C T}

Ultralow cycle fatigue (ULCF) failure was first observed on steel bridge piers in the Kobe earthquake, and the ultimate strength and ductility evaluation formulas of thin-walled steel bridge piers were established. In this study, parametric analysis of steel piers was carried out to study the influence of the structural parameters on the ULCF damage evolution. The evolution of the ULCF damage of the base metal, the deposited metal, and the heat-affected zones was studied based on two types of steel piers with hollow box and pipe sections. Then, practical formulas to predict the ULCF damage level of steel piers under cyclic loading were proposed. Finally, the proposed formulas were validated by comparisons with the experimental results. The results show that the heat-affected zone is more vulnerable to ULCF failure than the base metal and the deposited metal. Moreover, the practical formulas to predict the ULCF damage ind ex of the steel piers under cyclic loading were proposed, and the formulas effectively predicted the ULCF crack of the steel piers.
ART I CLE H IS TORY

$\begin{array}{ll}\text { Received: } & \text { 17 September } 2020 \\ \text { Revised: } & 7 \text { May } 2021 \\ \text { Accepted: } & 7 \text { May } 2021\end{array}$

\section{KEYWOR D S}

Cyclic void growth model;

Damage index;

Structural steel;

Steel bridge piers

Ultralow cycle fatigue

Copyright (C) 2021 by The Hong Kong Institute of Steel Construction. All rights reserved.

\section{Introduction}

For steel structures, the prevention of fracture is always a main concern for engineering design. At present, a great number of steel piers with hollow boxes or pipe sections are still widely used as substructures in highway bridges. During the 1995 Kobe earthquake, in addition to the traditional buckling failure mode, ultralow cycle fatigue (ULCF) failure occurred on steel bridge piers [15]. Then, the failure modes and the corresponding thresholds for this type of structure were studied by many researchers. The ultimate strength evaluation formulas of thin-walled steel plates and steel bridge piers, which are usually controlled by their buckling behavior, have been established. Meanwhile, ULCF failure of steel materials and joints can be predicted numerically based on the micromechanics, for example, the cyclic void growth model (CVGM). To date, the applicability of the ultimate strength evaluation formulas and the CVGM has been verified by some experiments. However, without the prediction formulas of ULCF damage, it is not clear in the design stage when the ULCF failure will determine the structural seismic safety.

After the 1995 Kobe earthquake, much research has been conducted on the seismic resistance and ultimate ductility of steel bridge piers. Zheng et al. [4] studied the ductility capacity of thin-walled steel box columns with and without longitudinal stiffeners. A failure strain was employed to define the ductility of steel columns, and the corresponding empirical formulas were developed based on the parametric analysis results. Kono et al. [5] investigated the ultimate deformation formula for steel box columns. The empirical formulas proposed in their study have a rather wide scope of application. Ge et al. [6] and Usami et al. [7] proposed empirical formulas of the ultimate strength for steel bridge piers with rectangular sections, which can consider the influence of the stiffener's slenderness. Based on the elastic-plastic finite deformation analysis, Ge et al. [8] proposed empirical formulas of strength and ductility for steel bridge piers with hollow pipe sections. With the efforts of these researchers, the ultimate strength and ductility, which are controlled by the buckling of steel piers under seismic loading, have been established. Some relevant guidelines can be found in bridge seismic design specifications. For example, Japanese specifications have stipulated the ductility capacity of thin-walled steel bridge piers [9]. Additionally, the limited slenderness ratio, width-to-thickness ratio and radius-thickness ratio for axial compressive or flexural dominant steel members have been provided by the AASHTO specifications [10].

The traditional empirical technique used to predict ULCF failure of structural steels is the Coffin-Manson formula [11-13]. However, the triaxial stress state in the crack initiation site is not considered in the formula, making it more applicable for uniaxial stress conditions. Therefore, the method based on microscopic damage mechanisms has attracted increased attention. In 1969, Rice et al. [14] studied the ductile growth rate of a single spherical void in an infinite ideal elastic-plastic continuum, and the void growth model was first proposed in their study. Through a series of tests and studies, Kanvinde et al. [15-18] proposed the cyclic void growth model to predict crack initiation for structural steels under cyclic loading. In the CVGM, the loading cycles are divided into tensile and compressive types based on the sign of the stress triaxiality for a certain material point. To facilitate the application of the micromechanical model, Liao et al. [19-20] and Yin et al. [21] calibrated the parameters in the CVGM by material tests and scanning electron microscope tests. Li et al. [22] proposed a new CVGM parameter calibration method to extend the scope of its application to a relatively lower-stress triaxiality condition. Moreover, the effect of the damage degradation parameter on the prediction of ULCF failure in steel bridge piers was discussed by them. Zhou et al. [23-24] and Wang et al. [25] conducted ULCF tests of steel joints under cyclic loads. Through the comparison of the prediction and the test results, they reported that the CVGM is a promising approach to predict the ULCF failure of steel structures. Xie et al. [26] studied the seismic damage characteristics of a thin-walled steel arch bridge considering both the strength and the ULCF failure modes. They found that the steel bridge experienced ULCF failure in its arch springing without apparent buckling failure.

During a strong earthquake, no matter which kind of failure mode is encountered for a steel bridge pier, it is fatal for the entire structure [1, 26-27]. The ultimate strength/ductility evaluation formulas of thin-walled steel bridge piers have been established. However, the ULCF damage prediction formulas are not yet available. Thus, the sequential occurrence of different failure modes for a steel bridge pier cannot be easily estimated. The use of the CVGM is a combination of complex FE modeling and void growth calculation. At present, it is not widely used because of the high computational cost and the substantial effort required for FE modeling. Therefore, the ULCF damage prediction formulas are much in need, especially in the design stage.

To establish the ULCF damage prediction formulas of single-column type bridge piers, parametric analysis was carried out in this study. A user subroutine UVARM coded by Fortran was utilized to track the evolution of the ULCF damage during the analysis. Two types of steel piers with hollow boxes or pipe sections were considered. The evolution of the ULCF damage of the base metal, the deposited metal, and the heat-affected zones was studied. The influence of the design parameters, including the diameter-to-thickness ratio, width-tothickness ratio, slenderness ratio and axial compression ratio, on the evolution of ULCF damage was obtained. Then, practical formulas to predict the extent of ULCF damage of the steel piers under cyclic loading were proposed. Finally, the proposed formulas were validated by comparisons with the experimental results.

\section{CVGM for ULCF failure prediction}


The crack initiation of ULCF is ductile, and the fracture process depends on microvoid nucleation, dilation, contraction, and coalescence. Based on the void growth theory of Rice et al. [14], Kanvinde et al. [15-18] proposed the CVGM for predicting the ULCF of structural steels. Zhou et al. [23-24] applied the CVGM to investigate the ULCF performance of beam-column joints, thereby validating the effectiveness of the model at the structural level Considering the different effects of compression and tension, the CVGM index $V G I_{\text {cyclic }}$ is defined as:

$$
V G I_{\text {cyclic }}=\sum_{\text {tensile-cycles }} \int_{\varepsilon_{1}}^{\varepsilon_{2}} \exp (|1.5 T|) \mathrm{d} \varepsilon_{\text {eq }}-\sum_{\text {compressive-cycles }} \int_{\varepsilon_{1}}^{\varepsilon_{2}} \exp (|1.5 T|) \mathrm{d} \varepsilon_{\text {eq }}
$$

where $\mathrm{d} \varepsilon_{\text {eq }}$ denotes the increment of equivalent plastic strain, $\varepsilon_{1}$ and $\varepsilon_{2}$ are the upper and lower plastic strain in the integral, respectively, and $T$ is the stress triaxiality (ratio of the mean stress to the von Mises effective stress).

The critical void growth index of the ULCF fracture is related to that of the monotonic tensile fracture. Based on test data and finite-element analysis, an exponential decay function is selected to express the critical void growth parameter for cyclic loading.

$$
V G I_{\text {cyclic }}^{\text {critical }}=\eta \exp \left(-\lambda_{\mathrm{CVGM}_{\mathrm{eq}}} \varepsilon_{\mathrm{e}}\right)
$$

where $\eta$ is the toughness parameter related to the material property, and it is actually the monotonic counterpart of $V G I_{\text {cyclic }}^{\text {critical }}$, and $\lambda_{\mathrm{CVGM}}$ is a materialdependent damageability coefficient. The cumulative equivalent plastic strain $\varepsilon_{\mathrm{eq}}$ in the equation is calculated at the beginning of each tensile excursion.

ULCF fracture is thought to occur when $V G I_{\text {cyclic }}$ exceeds its critical value $V G I_{\text {cyclic }}^{\text {critical }}$ :

$V G I_{\text {cyclic }}=V G I_{\text {cyclic }}^{\text {critical }}$

A new damage index $D_{0}$ is defined in this study as shown in Eq. (4) to illustrate the ULCF fracture damage evolution process. Thus, $D_{0}=0$ indicates no damage, and ductile crack initiation is predicted when $D_{0}$ reaches 1.0.

$$
D_{0}=\frac{\left(V G I_{\text {cyclic }}\right)_{\max }}{V G I_{\text {cyclic }}^{\text {critical }}}
$$

\section{Structural design and numerical models}

\subsection{Design parameters}

The stability and ductility of thin-walled piers with hollow sections are considered to be influenced by some key parameters $[9,28]$, such as the slenderness ratio $\lambda$, the diameter-to-thickness ratio $R_{\mathrm{t}}$ for a circular pier and the width-to-thickness ratio $R_{\mathrm{R}}$ of the subpanel for a rectangular pier.

$$
\left\{\begin{array}{l}
\lambda=\frac{2 h}{r} \cdot \frac{1}{\pi} \sqrt{\frac{\sigma_{\mathrm{y}}}{E}} \\
R_{\mathrm{t}}=\frac{R}{t} \cdot \frac{\sigma_{\mathrm{y}}}{E} \sqrt{3\left(1-\mu^{2}\right)} \\
R_{\mathrm{R}}=\frac{B}{t} \sqrt{\frac{\sigma_{\mathrm{y}}}{E} \frac{12\left(1-\mu^{2}\right)}{4 n^{2} \pi^{2}}}
\end{array}\right.
$$

In the above equations, $h$ is the height of the column, $r$ is the radius of gyration in the bending direction for the section, $\sigma_{y}$ is the yield strength of the steel, $E$ is the Young's modulus, $\mu$ is the Poisson's ratio, $R$ is the radius of the circular pier, $t$ is the thickness of the steel plate, $B$ is the flange width of the rectangular pier, and $n$ denotes the number of subpanels into which the plate is divided by the longitudinal stiffeners.

\subsection{Loading method and numerical model}

Fig. 1 shows a schematic view of single-column type bridge piers with hollow boxes or pipe sections. The cantilever piers are fixed to the ground in their bottom and subjected to a constant axial force $N$ and a cyclic horizontal force $H$. The variable $a$ is the distance between each diaphragm, $D$ is the depth of the rectangular section, and $a^{\prime}$ is the transverse spacing between each longitudinal stiffener.

To study the influence of the design parameters on the structural failure mode, 22 circular piers and 24 rectangular piers are designed with different structural parameters for the parametric analysis. For the circular piers, the parameters are set within the following ranges: the radius-to-thickness ratio $0.024 \leq R_{\mathrm{t}} \leq 0.095$, the slenderness ratio $0.197 \leq \lambda \leq 0.459$, the axial compression ratio $0.0 \leq N / N_{\mathrm{y}} \leq 0.3$ ( $N$ donates the applied axial load and $N_{\mathrm{y}}$ denotes the yield strength of the entire section) and the diaphragm spacing ratio $0.0 \leq \alpha(=a / R) \leq 3.0$. For the rectangular piers, the parameters are set within the following ranges: the width-to-thickness ratio $0.270 \leq R_{R} \leq 0.524$, the slenderness ratio $0.215 \leq \lambda \leq 0.573$, the axial compression ratio $0.0 \leq N / N_{\mathrm{y}} \leq 0.3$ and the diaphragm spacing ratio $0.556 \leq \alpha(=a / B) \leq 1.222$. Thus, all the parameters herein have ranges wide enough to satisfy the pier design demands $[9,28]$.

The horizontal cyclic load $H$ applied at the top end of the piers can be equivalent to a forced displacement $\delta$. That is, apart from a constant axial force induced by the weight of the superstructure, the pier is subjected to a horizontal cyclic displacement with increasing amplitudes for every 3 loops, as shown in Fig. 2. The variable $\delta_{\mathrm{y}}$ is the horizontal yield displacement corresponding to the yield thrust $H_{\mathrm{y}}$ of the pier.

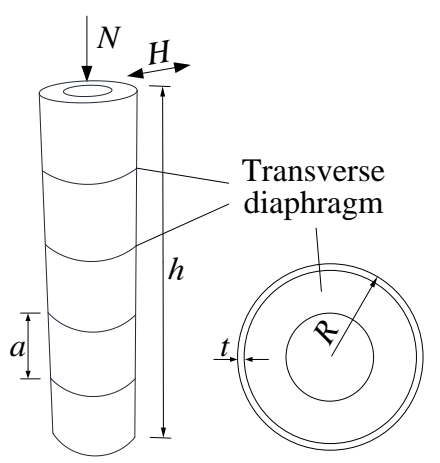

(a) Circular piers

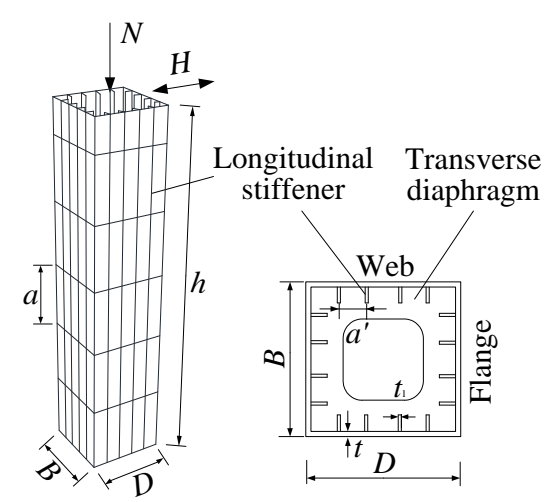

(b) Rectangular piers

Fig. 1 Structural design and loading method of steel piers

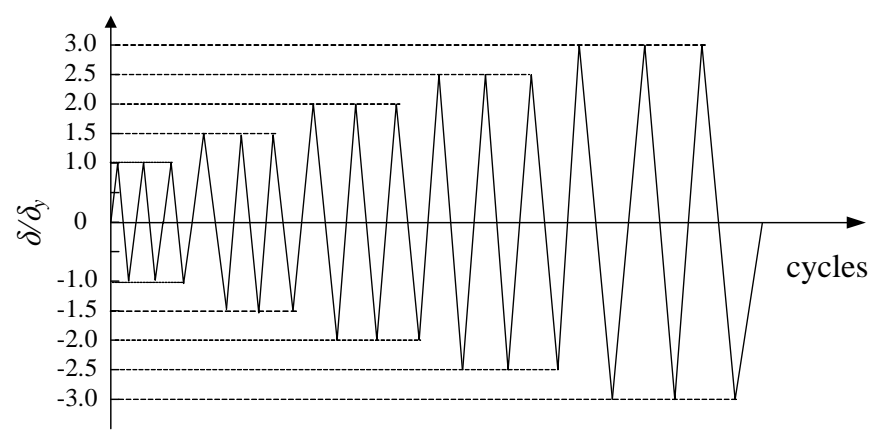

Fig. 2 Cyclic loading method

Numerical models of the steel piers with different structural parameters were constructed using the commercial software ABAQUS. For each steel pier two individual models were created. To take into account the local deformations of the plate near the base and the local strain in the weld region, a hybrid model with two different types of elements was adopted. Fig. 3 shows the models and the element discretization. The shell elements were used to model the steel plates within a distance of twice the length of the transverse diaphragm spacing $L_{\mathrm{d}}$ near the base. Parts with slight or no seismic damage above the second diaphragm from the base were modeled by the fiber beam elements. Thus, both the computational accuracy and the cost can be considered. The MPC-beam interaction was used as the linkage between the beam and the shell elements. 
The deformation history during loading around the edges of the most dangerous region near the base, which contains the heat-affected zone, the deposited metal, and the base metal, can be obtained. Then, a solid element model of the critical region was constructed with the deformation history applied on its edges. The dimensions of the shell and solid elements are less than $0.25 \mathrm{~mm}$, thereby satisfying the characteristic-length requirement of the CVGM. For the hybrid element model, approximately 25,000 elements were used, and the transverse section of the beam element was divided into 145 fibers. For the solid element model, approximately 48,000 elements were used.

Chaboche's combined hardening constitutive model, which can account for the kinematic and isotropic hardening effect of the material, was adopted since the CVGM parameter calibration was conducted with this kind of constitutive law [19-22]. The mechanical properties of the heat-affected zone, the deposited metal, and the base metal are different from each other. Table 1 shows the mechanical parameters of Q345, Chinese steel with a nominal yield strength of $345 \mathrm{MPa}$, in Chaboche's combined hardening model [22, 29]. The plastic modulus is continuously transformed during the loading, thereby ensuring the smooth transition of the stress-strain curve. The isotropic hardening effect is reflected by changing the yield surface radius $\sigma_{0}$, which is defined as a nonlinear function of the equivalent plastic strain $\varepsilon_{\mathrm{p}}$, as follows.

$$
\sigma_{0}=\left.\sigma\right|_{0}+Q_{\infty}\left(1-e^{-b \varepsilon_{\mathrm{p}}}\right)
$$

where $\left.\sigma\right|_{0}$ is the initial yielding strength, $Q_{\infty}$ is the maximum hardening value of the yield surface, and $b$ is the ratio of the change in yield strength to the development of plastic strain.

The movement of the yield surface center $\alpha$ is treated as the kinematic hardening effect, where $\alpha$ is determined by a group of back stress $\alpha_{\mathrm{k}}$.

$$
\left\{\begin{array}{l}
\alpha=\sum_{i=1}^{N} \alpha_{k} \\
\alpha_{k}=\frac{C_{k}}{\gamma_{k}}\left(1-e^{-\gamma_{k} \varepsilon_{\mathrm{p}}}\right)+\alpha_{k, 1} e^{-\gamma_{k} \varepsilon_{\mathrm{p}}}
\end{array}\right.
$$

where $C_{\mathrm{k}}$ is the initial modulus of the kinematic hardening, and $\gamma_{\mathrm{k}}$ is the ratio of the kinematic hardening modulus change to the plastic strain.

During the calculation, both the material and the geometric nonlinearities were considered. A user subroutine UVARM was integrated into the FE analysis to track the evolution of the ULCF damage index during the loading. Thus, the damage indices of the entire structure can be seen directly in the visualization module of the software.

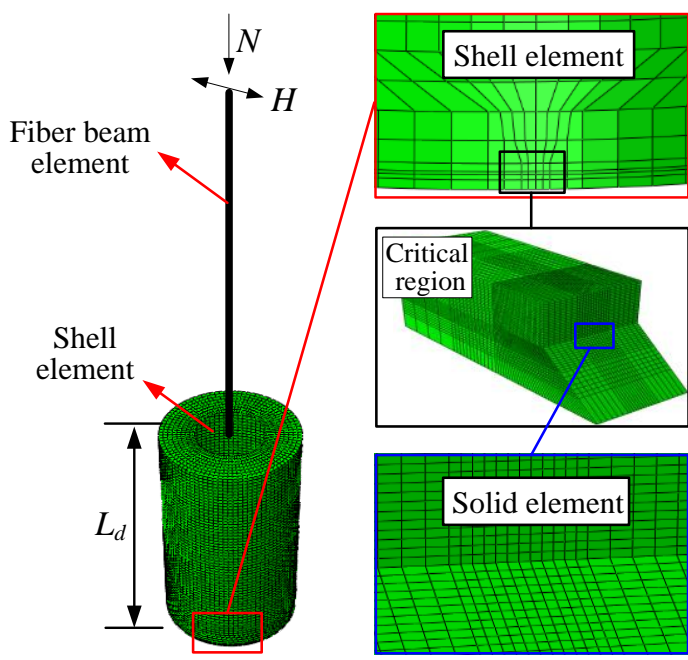

(a) Circular piers

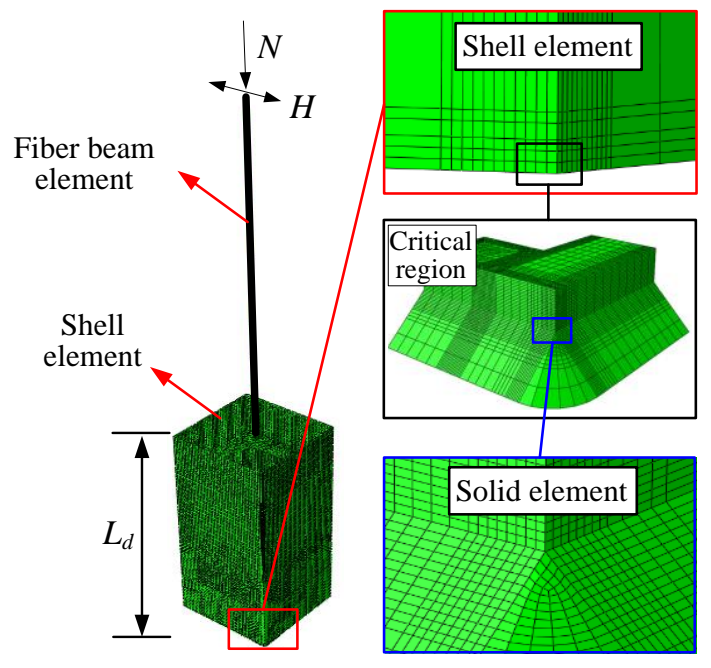

(b) Rectangular piers

Fig. 3 Numerical models and element discretization

Table 1

Material parameters of Q345 steel

\begin{tabular}{cccccccccccc}
\hline Material & $\begin{array}{c}\left.\sigma\right|_{0} \\
(\mathrm{MPa})\end{array}$ & $\begin{array}{c}Q_{\infty} \\
(\mathrm{MPa})\end{array}$ & $b$ & $\begin{array}{c}C_{1} \\
(\mathrm{MPa})\end{array}$ & $\gamma_{1}$ & $\begin{array}{c}C_{2} \\
(\mathrm{MPa})\end{array}$ & $\gamma_{2}$ & $\begin{array}{c}C_{3} \\
(\mathrm{MPa})\end{array}$ & $\gamma_{3}$ & $\eta$ & $\lambda_{\mathrm{CVGM}}$ \\
\hline Base metal & 354.10 & 13.2 & 0.6 & 44373.7 & 523.8 & 9346.6 & 120.2 & 946.1 & 18.7 & 2.55 & 0.20 \\
Heat-affected zone & 312.57 & 9.8 & 0.7 & 32242.4 & 199.2 & 3858.5 & 43.1 & 329.2 & 0.3 & 2.53 & 0.33 \\
Deposit metal & 428.45 & 17.4 & 0.4 & 12752.3 & 160.0 & 1111.2 & 160.0 & 630.5 & 26.0 & 2.63 & 0.25 \\
\hline
\end{tabular}

\section{ULCF damage evolution under cyclic loading}

The horizontal load-displacement curves and the corresponding envelope curves at the top of the steel piers were obtained during the loading. For a thinwalled structure, the ultimate strength and ductility are usually controlled by the buckling behavior. Consequently, some critical states based on the envelope curves were adopted to check the value of the ULCF damage index. Three critical states were selected: the peak point on the envelope curve [9], the point when the horizontal strength on the envelope curve has exceeded the peak value and decreased to $95 \%$ of the ultimate strength [4, 7], and the point when the horizontal strength on the envelope curve has exceeded its peak value and decreased to $90 \%$ of the ultimate strength [30].

Fig. 4 shows the ULCF damage indices of the circular pier with different design parameters under the three critical buckling states. Similarly, Fig. 5 shows the ULCF damage indices of the rectangular pier. In these figures, $H_{\mathrm{m}}$ is the peak strength on the envelope curve. Thus, $1.00 H_{\mathrm{m}}, 0.95 \mathrm{H}_{\mathrm{m}}$, and $0.90 \mathrm{H}_{\mathrm{m}}$ denote the three critical states previously defined, and $D_{\mathrm{B}}, D_{\mathrm{D}}$, and $D_{\mathrm{H}}$ denote the ULCF damage indices corresponding to the base metal, the deposited metal, and the heat-affected zone at the bottom of the pier, respectively. The ULCF damage indices gradually increase as the horizontal resistance of the piers reaches the peak value and then decreases. If one of the parameters of the axial compression ratio, the radius-to-thickness ratio, and the width-to-thickness ratio is large enough (e.g., $N / N_{\mathrm{y}}>0.3, R_{\mathrm{t}}>0.05$, or $R_{R}>0.5$ ), the ULCF damage indices are rather small $(D<1.0)$. This indicates that the buckling failure mode plays a dominant role in these circumstances. The heat-affected zone is more vulnerable to ULCF failure than the base metal and the deposited metal since the damage index $D_{\mathrm{H}}$ is usually larger than indices $D_{\mathrm{B}}$ and $D_{\mathrm{D}}$. 

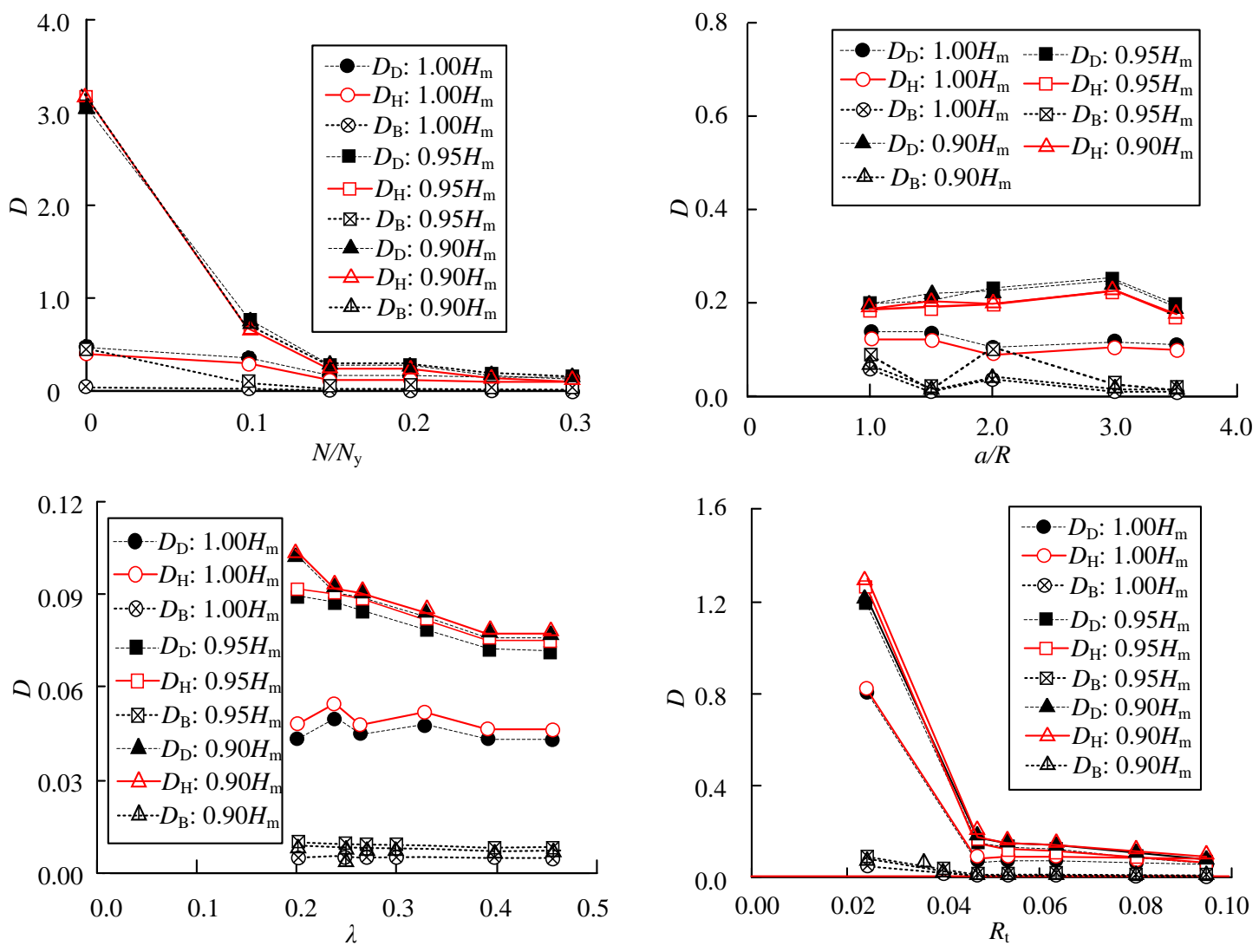

Fig. 4 ULCF damage indices of the circular piers under the critical states
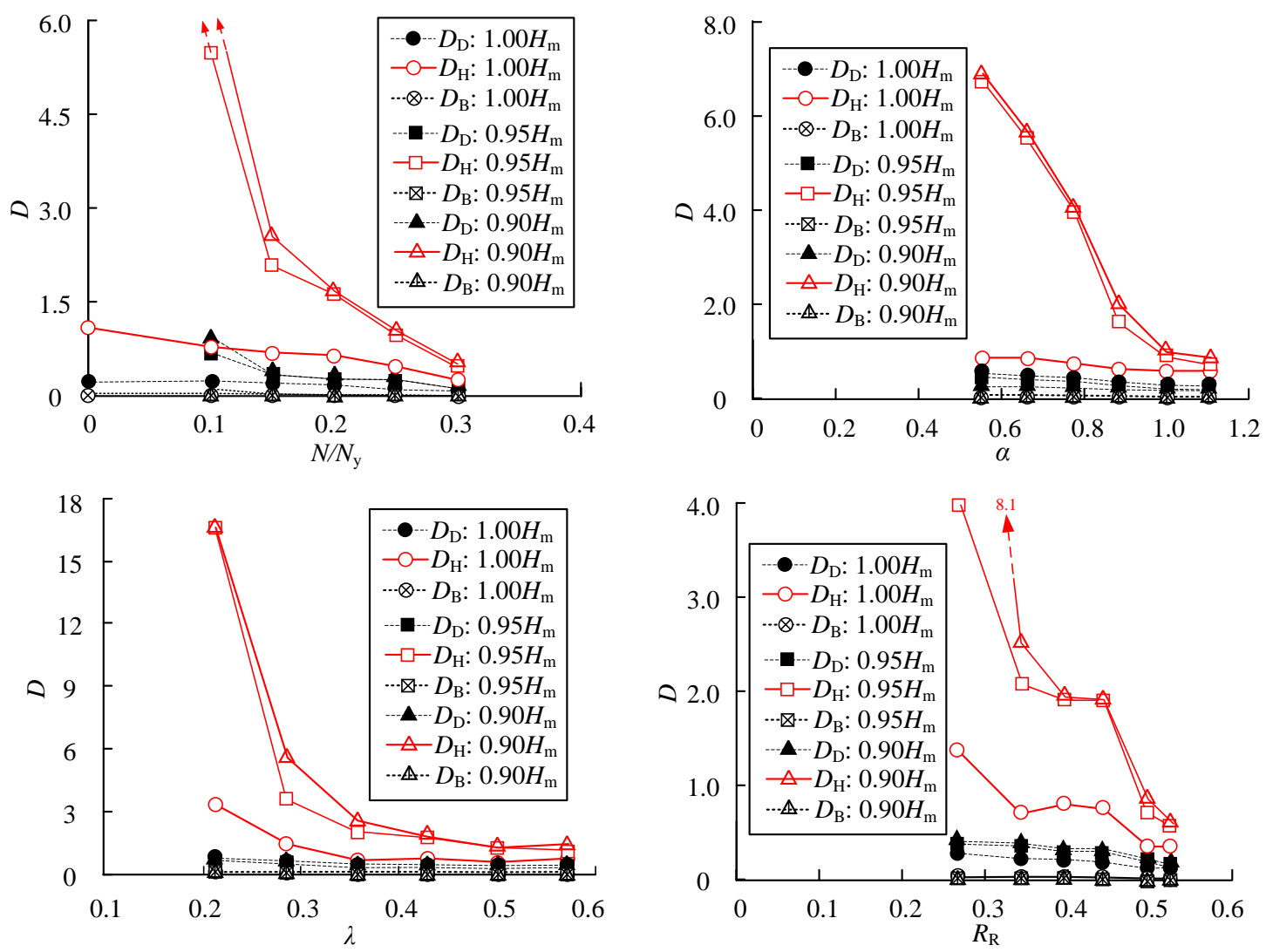

Fig. 5 ULCF damage indices of the rectangular piers under the critical states 


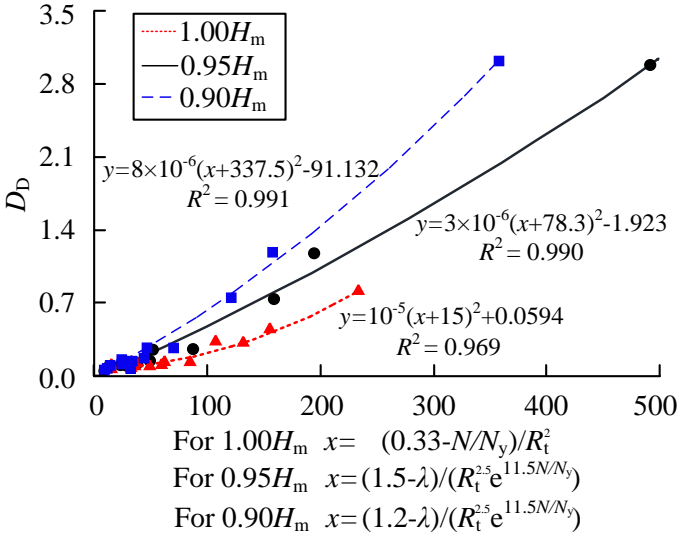

(a) $D_{\mathrm{D}}$ of the circular piers

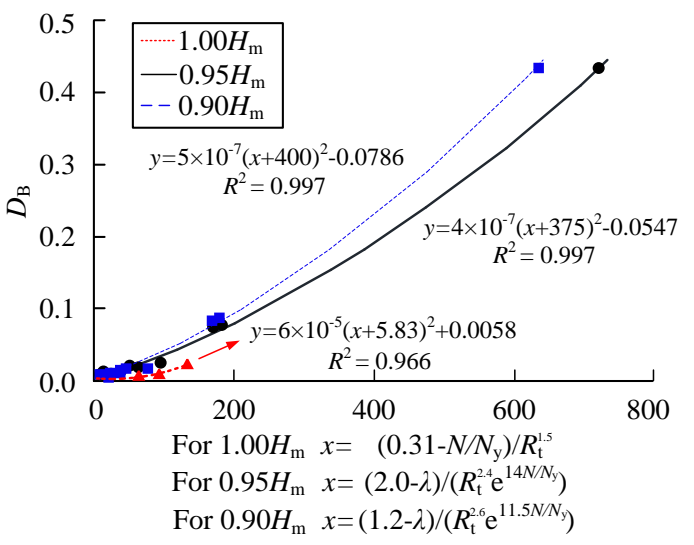

(c) $D_{\mathrm{B}}$ of the circular piers

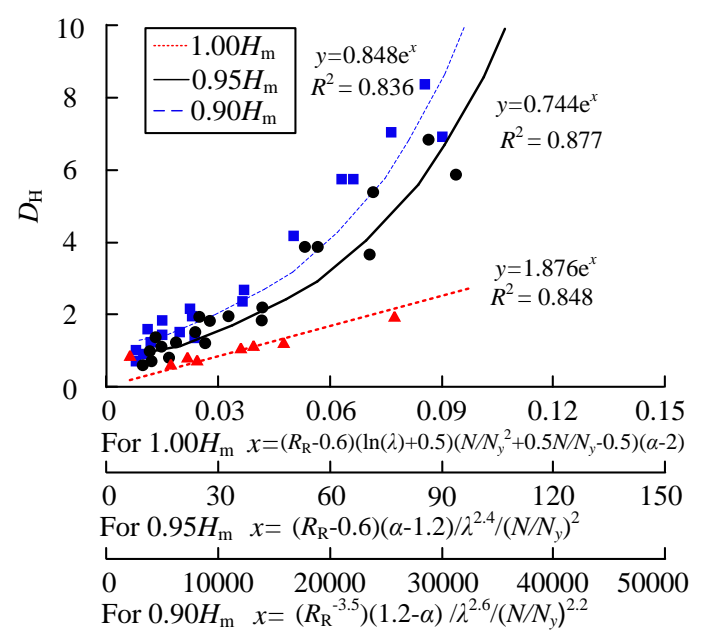

(e) $D_{\mathrm{H}}$ of the rectangular piers

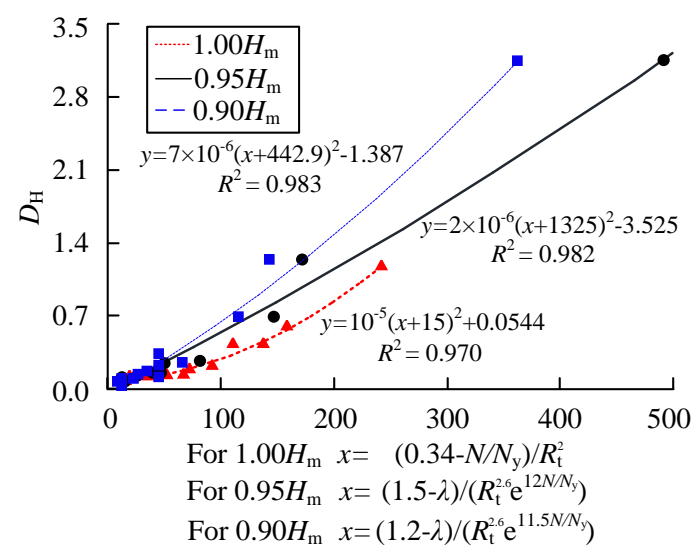

(b) $D_{\mathrm{H}}$ of the circular piers

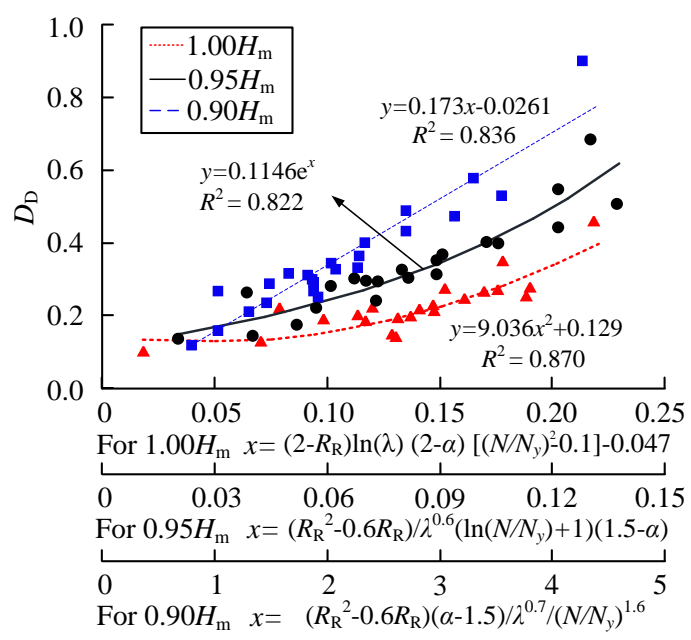

(d) $D_{\mathrm{D}}$ of the rectangular piers

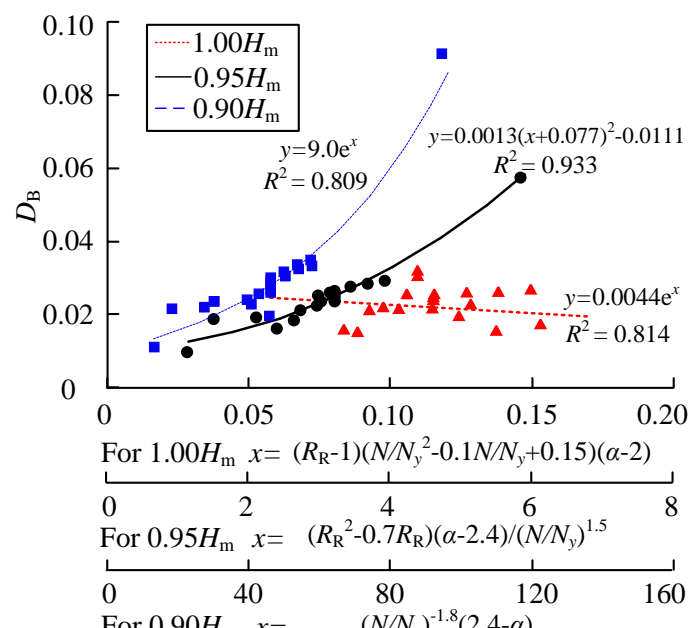

(f) $D_{\mathrm{B}}$ of the rectangular piers

Fig. 6 ULCF damage indices of the pier bottoms under the critical states

Fig. 6 shows the fitting relationship between the ULCF damage indices and the designed structural parameters of the steel bridge piers. Eqs. (8)-(10) are the ULCF damage indices fitting formulas for the circular piers, while Eqs. (11)-(13) are the fitting formulas for the rectangular piers. For most cases, the satisfactory accuracy of regression analysis can be achieved since the determination coefficients, $R^{2}$, of the estimations are all above 0.8 . Moreover, for the piers with circular sections, if the radius-to-thickness ratio is rather small (e.g., $R_{\mathrm{t}}<0.03$ ), the ULCF failure may occur at the heat-affected zone near the base when the horizontal strength on the envelope curve just exceeds its peak value. For the piers with rectangular sections, the order of the failure modes is more complicated. When the width-to-thickness ratio of the flange plate, the slenderness ratio, and the diaphragm spacing ratio are all small enough (e.g., $R_{R}<0.3, \lambda<0.3$ and $\alpha<0.8$ ), ULCF failure occurs at the heat-affected zone before the horizontal ultimate strength state. 


$$
\begin{aligned}
& D_{D}=1 \times 10^{-5} \cdot\left(\frac{0.33-N / N_{y}}{R_{t}^{2}}+15\right)^{2}+0.0594 \\
& \left\{D_{H}=1 \times 10^{-5} \cdot\left(\frac{0.34-N / N_{y}}{R_{t}^{2}}+15\right)^{2}+0.0544 \quad \text { for circular section at } 1.00 H_{\text {max }}\right. \text { state } \\
& D_{B}=6 \times 10^{-5} \cdot\left(\frac{0.31-N / N_{y}}{R_{t}^{1.5}}-5.833\right)^{2}+0.00586 \\
& D_{D}=3 \times 10^{-6} \cdot\left(\frac{1.5-\lambda}{R_{t}^{2.5} \exp \left(11.5 \mathrm{~N} / N_{y}\right)}+783.333\right)^{2}-1.923 \\
& \left\{D_{H}=2 \times 10^{-6} \cdot\left(\frac{1.5-\lambda}{R_{t}^{2.6} \exp \left(12 N / N_{y}\right)}+1325\right)^{2}-3.525 \quad \text { for circular section at } 0.95 H_{\text {max }}\right. \text { state } \\
& D_{B}=4 \times 10^{-7} \cdot\left(\frac{2-\lambda}{R_{t}^{2.4} \exp \left(14 N / N_{y}\right)}+375\right)^{2}-0.0547 \\
& D_{D}=8 \times 10^{-6} \cdot\left(\frac{1.2-\lambda}{R_{t}^{2.5} \exp \left(11 N / N_{y}\right)}+337.5\right)^{2}-91.132 \\
& \left\{D_{H}=7 \times 10^{-6} \cdot\left(\frac{1.2-\lambda}{R_{t}^{2.6} \exp \left(11.5 N / N_{y}\right)}+442.857\right)^{2}-1.387 \text { for circular section at } 0.90 H_{\text {max }}\right. \text { state } \\
& D_{B}=5 \times 10^{-7} \cdot\left(\frac{1.2-\lambda}{R_{t}^{2.6} \exp \left(11.5 N / N_{y}\right)}+400\right)^{2}-0.0786 \\
& \left\{\begin{array}{l}
D_{D}=9.0362 \cdot\left\{\left(R_{\mathrm{R}}-2.0\right) \cdot \ln (\lambda) \cdot(\alpha-2.0) \cdot\left[\left(N / N_{\mathrm{y}}\right)^{2}-0.1\right]-0.047\right\}^{2}+0.129 \\
D_{H}=1.876 \cdot \exp \left\{\left(R_{\mathrm{R}}-0.6\right) \cdot(\ln \lambda+0.5) \cdot\left[\left(N / N_{\mathrm{y}}+0.25\right)^{2}-0.5625\right] \cdot(\alpha-2.0)\right\} \text { for rectangular section at } 1.00 H_{\text {max }} \text { state } \\
D_{B}=0.0044 \cdot \exp \left\{\left(R_{\mathrm{R}}-1.0\right) \cdot\left[\left(N / N_{\mathrm{y}}-0.05\right)^{2}+0.1475\right] \cdot(\alpha-2.0)\right\}
\end{array}\right. \\
& D_{D}=0.1146 \cdot \exp \left\{\frac{12.13 \cdot\left(R_{\mathrm{R}}^{2}-0.6 R_{\mathrm{R}}\right) \cdot\left[\ln \left(N / N_{y}\right)+1.0\right] \cdot(1.5-\alpha)}{\lambda^{0.6}}\right\} \\
& \left\{D_{H}=0.7435 \cdot \exp \left\{\frac{\left(R_{\mathrm{R}}-0.6\right) \cdot(\alpha-1.2)}{\lambda^{2.4} \cdot\left[\ln \left(N / N_{\mathrm{y}}\right)\right]^{2}}\right\} \quad \text { for rectangular section at } 0.95 H_{\text {max }}\right. \text { state } \\
& D_{B}=0.0013 \cdot\left[\frac{\left(R_{\mathrm{R}}^{2}-0.7 R_{\mathrm{R}}\right) \cdot(\alpha-2.4)}{\left(N / N_{\mathrm{y}}\right)^{1.5}}+0.077\right]^{2}-0.0111 \\
& \left\{\begin{array}{l}
D_{D}=0.173 \cdot\left(\frac{\left(R_{R}{ }^{2}-0.6 R_{R}\right) \cdot(\alpha-1.5)}{\lambda^{0.7} \cdot\left(N / N_{y}\right)^{1.6}}\right)-0.0261 \\
D_{H}=0.848 \cdot \exp \left(\frac{1.2-\alpha}{\lambda^{2.6} \cdot R_{R}^{3.5} \cdot\left(N / N_{y}\right)^{2.2}}\right) \quad \text { for rectangular section at } 0.90 H_{\text {max }} \text { state }
\end{array}\right. \\
& D_{B}=9.0 \cdot \exp \left[\frac{2.4-\alpha}{\left(N / N_{y}\right)^{1.8}}\right]
\end{aligned}
$$

\section{Comparison of the predicted index and the test results}

The results of the experimental tests carried out on the thin-walled steel piers were selected from the studies performed by Ge et al. [31-32]. Therefore, in this section, three steel piers with hollow rectangular sections are numerically analyzed. Then, the crack location and initiation time are compared with the experimental results.

Cross-sectional details of the specimens with rectangular sections are shown in Fig. 7. Table 2 presents the geometric dimensions and design parameters of the specimens. One end of the steel specimen is bolted directly to the fixed-base plate, and the other end is attached to a moving device. A constant vertical load $\left(N / N_{\mathrm{y}}=0.1\right)$, together with a similar cyclic horizontal loading as shown in Fig. 2, was applied to the top end. Crack initiation is defined at the time when the crack length extends $1 \sim 2 \mathrm{~mm}$ according to observations.

The same technique described in Section 3 is adopted here. In particular, shell elements were used to model the steel plates within a distance of 3 times the length of the transverse diaphragm spacing near the base. Parts with slight or no seismic damage above the third diaphragm from the base were modeled by fiber beam elements. The dimensions of shell and solid elements in the areas of concern are less than $0.25 \mathrm{~mm}$. For the hybrid element model, approximately 30,000 elements were used. For the solid element model, approximately 23,000 elements were used.

The comparisons of the lateral load-displacement hysteretic curves obtained by the test and the numerical analysis are shown in Fig. 8, in which the solid and dotted lines donate the hysteretic curves obtained by the test and the numerical analysis, respectively. The ULCF crack points are indicated in these figures. The load-displacement curves are identical in most cycles of load, while differences are observed in the last several cycles of the load. After the initiation, the crack propagated. Therefore, the hysteretic curves of specimens UB25-35 and UB35-35 obtained from the tests show a significant decrease. Because the strength deterioration caused by the ULCF crack is not considered in the numerical analysis, the difference can be observed between the hysteretic curves obtained by the test and the numerical analysis, especially in the last 
load cycle. In addition, the cracks in the test and the numerical analysis initiated at the heat-affected zones. It can be concluded that the numerical results fit very well with the test results.

Table 2

Parameters and dimensions of test specimens

\begin{tabular}{ccccccc}
\hline Specimen No. & $B(\mathrm{~mm})$ & $D(\mathrm{~mm})$ & $t(\mathrm{~mm})$ & $h(\mathrm{~mm})$ & $R_{\mathrm{R}}$ & $\lambda$ \\
\hline UB25-35C3P1 & 112 & 103 & 9.02 & 568 & 0.26 & 0.37 \\
UB35-45C3P1 & 152 & 143 & 9.02 & 998 & 0.37 & 0.47 \\
\hline
\end{tabular}

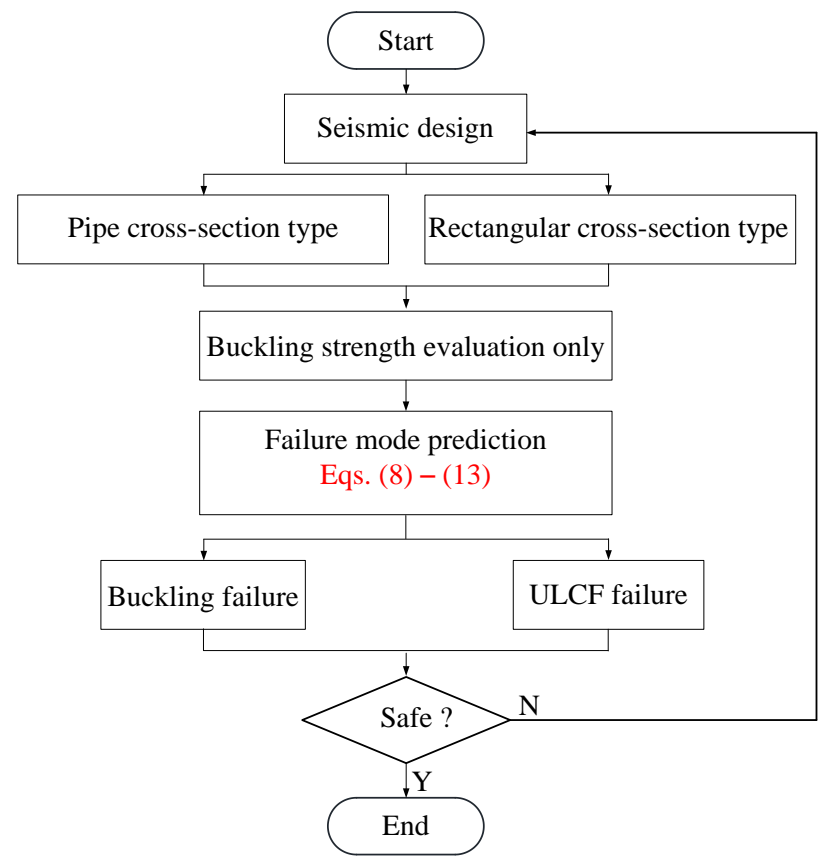

Fig. 7 Flowchart of the simplified seismic design procedure

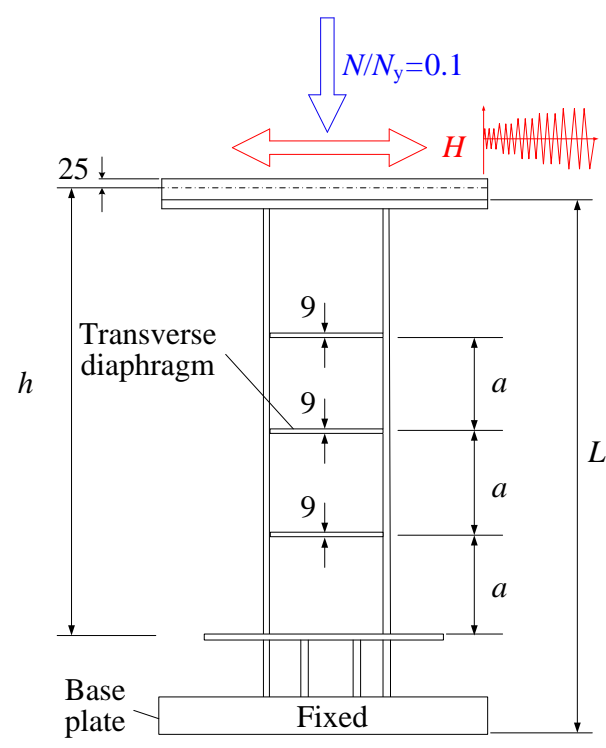

(a) Elevation view

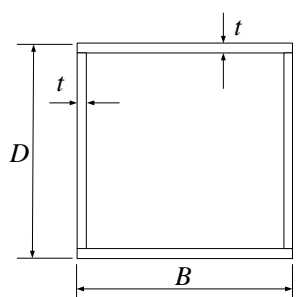

(b) Transverse section

Fig. 8 Test specimen (Unit: mm)

Fig. 9 shows the evolution of the ULCF damage indices along with the load cycles obtained from the numerical analysis. Both the crack initiation point and the ultimate strength state point are indicated in the figure. Fig. 10 shows the envelope curves of the load-displacement hysteretic loops obtained from the numerical analysis, in which the peak value of the strength and the ULCF crack points are indicated. The results show that the ULCF damage index of the heat-affected zone grew faster than those of the base metal and the deposited metal; therefore, the crack initiated in this region. In addition to specimen UB25-35, the bottoms of specimens U35-35 and UB35-45 cracked before the ultimate strength state, which means they first experienced ULCF failure rather than buckling failure. For specimen UB25-35, the crack initiated when the strength of the member exceeded its peak value and decreased to $98 \%$ of the ultimate strength. At the crack initiation moment, apparent buckling of the steel plates was not observed for the piers, as shown in Fig. 11.

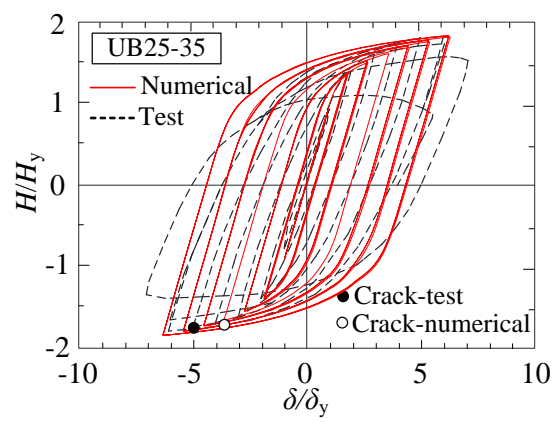

(a) UB25-35

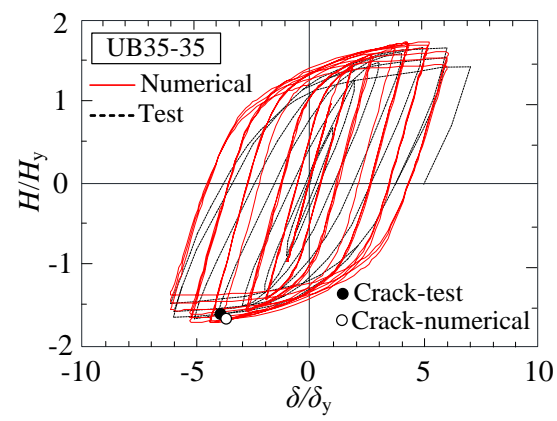

(b) UB35-35

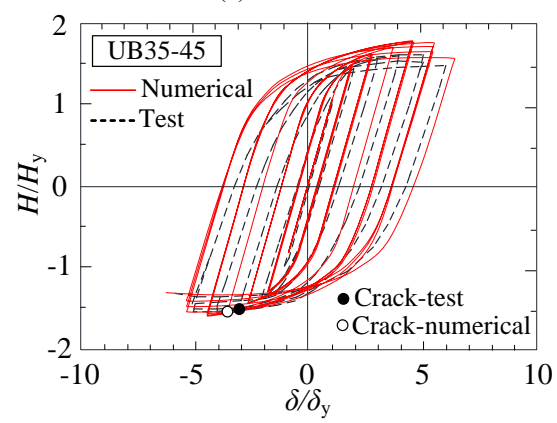

(c) UB35-45

Fig. 9 Comparison of the lateral load-displacement hysteretic curves

Table 3 compares the crack initiation points during loading. The differences between the numerical and experimental results are less than 2 cycles, and the errors between them are $8.1 \% \sim 14.2 \%$. This means that the ULCF damage index is effective in predicting ULCF crack initiation.

Table 3

Comparison of the crack initiation points

\begin{tabular}{cccc}
\hline \multirow{2}{*}{ Specimen } & \multicolumn{3}{c}{ Crack initiation } \\
\cline { 2 - 4 } & Test results & Numerical results $\left(D_{0}=1.0\right)$ & Error \\
\hline UB25-35C3P1 & -26.0 half-cycles & -22.3 half-cycles & $14.2 \%$ \\
UB35-35C3P1 & -22.0 half-cycles & -20.2 half-cycles & $8.1 \%$ \\
UB35-45C3P1 & -18.0 half-cycles & -20.4 half-cycles & $13.3 \%$ \\
\hline
\end{tabular}

To verify the applicability of the prediction formulas proposed in this study, the ULCF damage indices, which are obtained by the prediction formulas and the numerical analysis, at the ultimate strength state are compared as shown in Fig. 12. The prediction formulas, the numerical results and the test results all show that the most vulnerable region for the ULCF crack is the heat-affected zone near the base. The prediction formulas are reliable for predicting the ULCF damage index of thin-walled steel bridge piers. 


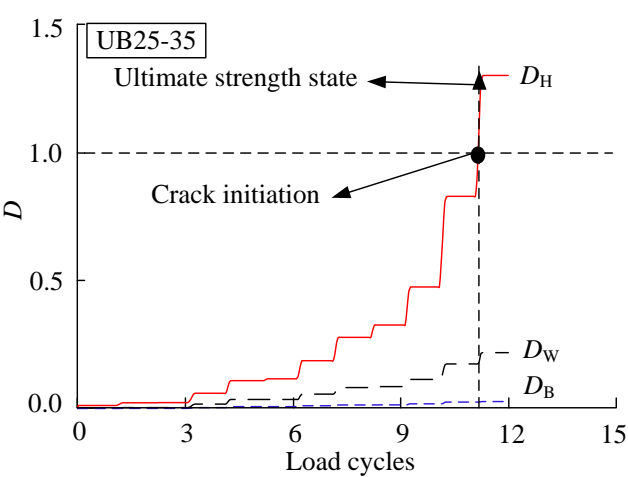

(a) UB25-35

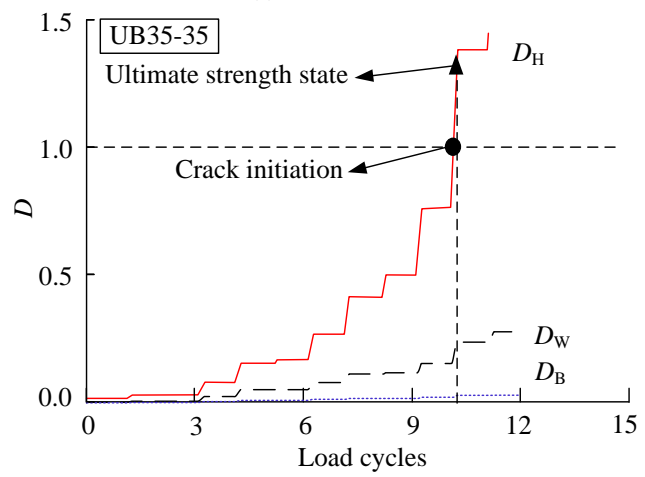

(b) UB35-35

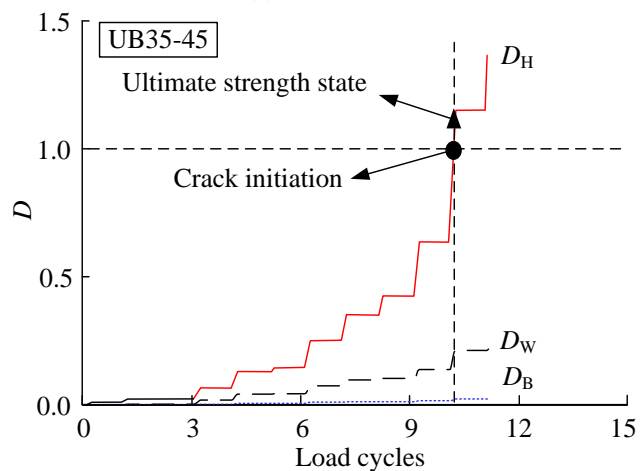

(c) UB35-45

Fig. 10 Evolution of the ULCF damage indices during cyclic loading

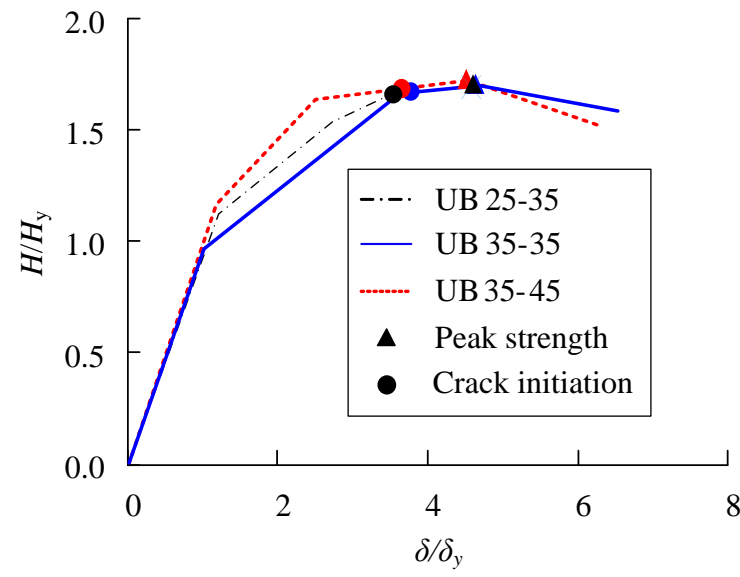

Fig. 11 ULCF failure points and the ultimate strength points of the piers

\section{Conclusions}

Parametric analysis of steel bridge piers with hollow boxes or pipe sections was carried out in this study. The influence of the design parameters on the ULCF damage evolution of steel piers was studied. Practical formulas to predict the ULCF damage index were proposed. Some main conclusions can be drawn as follows.

(1) The ULCF damage indices gradually increase as the horizontal resistance of the piers reaches the peak value and then decreases. The heataffected zone is more vulnerable to ULCF failure than the base metal and the

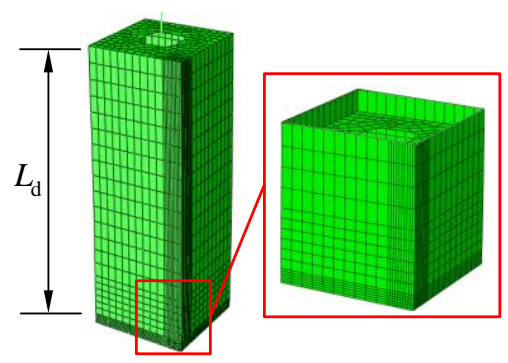

UB25-35

(a) UB25-35

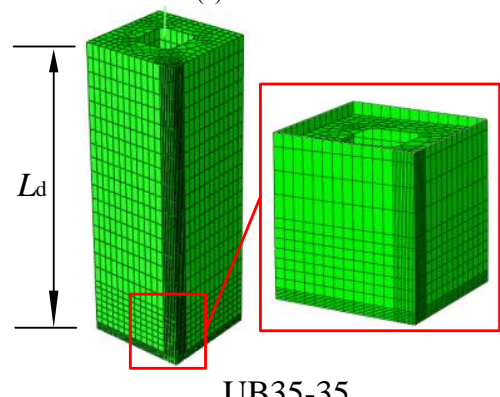

b) UB35-35

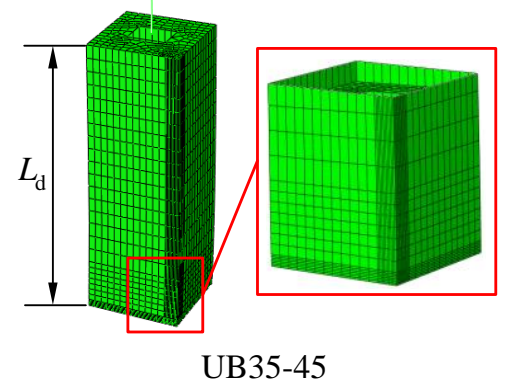

(c) UB35-45

Fig. 12 Local deformation of the steel plate at the ULCF failure point

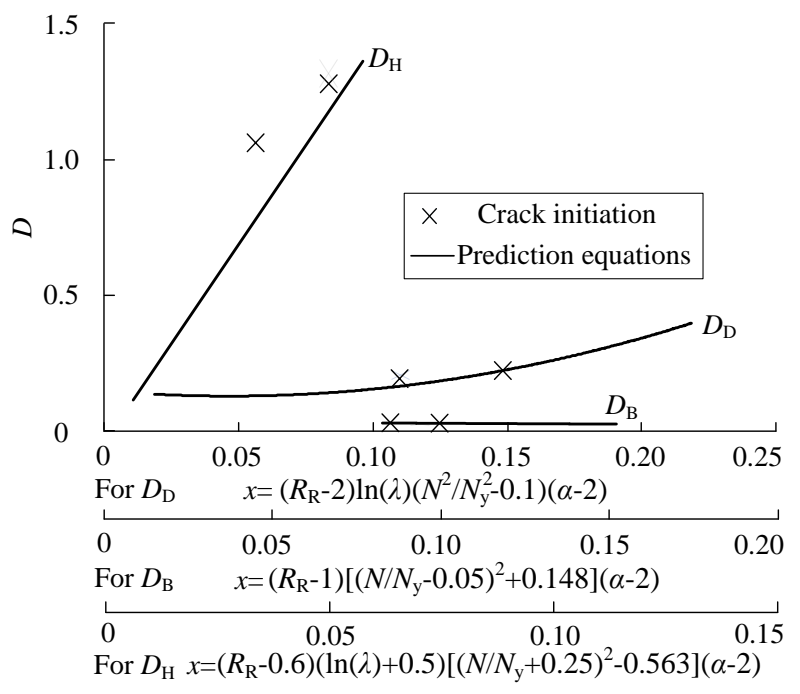

Fig. 13 Comparison between the calculated results and the numerical analysis

deposited metal

(2) If one of the structural parameters of the axial compression ratio, the radius-to-thickness ratio and the width-to-thickness ratio is large enough (e.g., $N / N_{\mathrm{y}}>0.3, R_{\mathrm{t}}>0.05$, or $R_{R}>0.5$ ), the buckling failure mode will play a dominant role in steel bridge piers under cyclic loading.

(3) For piers with circular sections, if the radius-to-thickness ratio is rather small (e.g., $R_{\mathrm{t}}<0.03$ ), the ULCF failure may occur at the heat-affected zone near the base when the horizontal strength on the envelope curve just exceeds its peak value. For piers with rectangular sections, when the width-to-thickness ratio of the flange plate, the slenderness ratio, and the diaphragm spacing ratio 
are all small enough (e.g., $R_{R}<0.3, \lambda<0.3$ and $\alpha<0.8$ ), ULCF failure will occur before the ultimate strength state.

(4) Practical formulas to predict the ULCF damage index of steel piers under cyclic loading are proposed in this study. The satisfactory accuracy of regression analysis can be achieved since the determination coefficients of the estimations are all above 0.8. Comparisons between the predicted results and the tests show that the proposed formulas are effective in predicting the ULCF crack of the steel piers.

\section{References}

[1] E. Watanabe, K. Sugiura, K. Nagata, Y. Kitane. Performances and damages to steel structure during the 1995 Hyogoken-Nanbu earthquake. Engineering Structures, 1998, 20(4):282-290

[2] T. Usami. Interim guidelines and new technologies for seismic design of steel structures. Tokyo: Committee on New Technology for Steel Structures (CNTSS), JSCE, 1996.

[3] J. J. Liang, H. B. Ge. Ultra-low-cycle fatigue failure of metal structures under strong earthquakes. Singapore: Springer Nature Singapore Pte Ltd, 2019.

[4] Y. Zheng, T. Usami, H. B. Ge. Ductility of thin-walled steel box stub-columns Journal of Structural Engineering, 2000, 126(11): 1304-1311.

[5] T. Kono, H. B. Ge, T. Usami. Re-examination of the ultimate strain formula for steel box stub-columns and its application in steel arch bridges. Proceedings of the 6th Symposium on Ductility Design Method for Bridges, Ductility Design Subcommittee, Tokyo, 2003: 323 328.

[6] H. B. Ge, S. B. Gao, T. Usami. Stiffened steel box columns. Part 1: cyclic behavior Earthquake Engineering and Structural. Dynamics, 2000, 29(11): 1691-1706.

[7] T. Usami, H. B. Ge, S. B. Gao. Stiffened steel box columns. Part 2: ductility evaluation. Earthquake Engineering and Structural. Dynamics. 2000, 29(11): 1707-1722.

[8] H. B. Ge, S. B. Gao, T. Usami. Numerical study on cyclic elasto-plastic behavior of steel bridge piers of pipe-sections without stiffeners. Japan Society of Civil Engineers, 1997, 577(41): 181-190. (In Japanese)

[9] Japanese Road Association. Specifications for highway bridges, Part V: Seismic design. Tokyo: Maruzen, 2012.

[10] AASHTO. Guide specifications for LRFD seismic bridge design. Washington DC: American Association of State Highway and Transportation Officials, 2nd edition, 2011.

[11] H. B. Ge, X. Q. Luo. A seismic performance evaluation method for steel structures against local buckling and extra-low cycle fatigue. Journal of Earthquake and Tsunami, 2011, 05(02):83-99.

[12] H. B. Ge, L. Kang. A damage index-based evaluation method for predicting the ductile crack initiation in steel structures. Journal of Earthquake Engineering, 2012, 16(5):623-643.

[13] L. Kang, H. B. Ge. Predicting ductile crack initiation of steel bridge structures due to extremely low-cycle fatigue using local and non-local models. Journal of Earthquake Engineering, 2013, 17(3):323-349.

[14] J. R. Rice, D. M. Tracey. On the ductile enlargement of voids in triaxial stress fields. Journal of the Mechanics and Physics of Solids, 1969, 17(3): 201-217.

[15] A. M. Kanvinde, G. G. Deierlein. Void growth model and stress modified critical strain model to predict ductile fracture in structural steels. Journal of Structural Engineering, ASCE, 2006, 132(12): 1907-1918.

[16] A. M. Kanvinde, G. G. Deierlein. Finite-element simulation of ductile fracture in reduced section pull-plates using micromechanics-based fracture models. Journal of Structural Engineering, ASCE, 2007, 133(5): 656-664.

[17] A. M. Kanvinde, G. G. Deierlein. Cyclic void growth model to assess ductile fracture

\section{Acknowledgments}

The work described in this paper was financially supported by the grants from the National Natural Science Foundation of China (No. 51708485), the Natural Science Foundation of Fujian Province (No. 2021J011062), the Jiangsu Planned Projects for Postdoctoral Research Funds (No. 1701191B) and the China Postdoctoral Science Foundation (No. 2017M611925), and their support is gratefully acknowledged by the authors.

initiation in structural steels due to ultra-low cycle fatigue. Journal of Engineering Mechanics, ASCE, 2007, 133(6), 701-712.

[18] A. M. Kanvinde, I. R. Gomez, M. Roberts. Strength and ductility of fillet welds with transverse root notch. Journal of Constructional Steel Research, 2009, 65(4): 948-958.

[19] F. F. Liao, W. Wang, Y. Chen. Parameter calibrations and application of micromechanical fracture models of structural steels. Structural Engineering and Mechanics, 2012, 42(2): 153 174

[20] F. F. Liao, M. Q. Wang, L. S. Tu. Micromechanical fracture model parameter influencing factor study of structural steels and welding materials. Construction and Building Materials, 2019, 215: 898-917.

[21] Y. Yin, S. Li, Q. Han, P. Lei. Calibration and verification of cyclic void growth model for 20Mn5QT cast steel. Engineering Fracture Mechanics, 2019, 206, 310-329.

[22] S. L. Li, X. Xie, Y. H. Liao. Improvement of Cyclic Void Growth Model for Ultra-Low Cycle Fatigue Prediction of Steel Bridge Piers. Materials, 2019, 12(10): 153-174.

[23] H. Zhou, Y. Wang, L. Yang. Seismic low-cycle fatigue evaluation of welded beam-to-column connections in steel moment frames through global-local analysis. International Journal of Fatigue, 2014, 64(7): 97-113.

[24] H. Zhou, Y. Wang, Y. Shi. Extremely low cycle fatigue prediction of steel beam-to-column connection by using a micro-mechanics-based fracture model. International Journal of Fatigue, 2013, 48(2): 90-100

[25] Y. Wang, H. Zhou, Y. Shi. Fracture behavior analyses of welded beam-to-column connections based on elastic and inelastic fracture mechanics. International Journal of Steel Structures, 2010, 10(3): 253-265.

[26] X. Xie, H. Q. Zhuge, Z. Z. Tang. Damage characteristics of thin-walled steel arch bridges subjected to in-plane earthquake action. Journal of Constructional Steel Research, 2018, $151: 70-82$

[27] H. Kuwamura, K. Yamamoto. Ductile Crack as Trigger of Brittle Fracture in Steel. Journal of Structural Engineering, 1997, 123(6):729-735.

[28] W. F. Chen, L. Duan. Bridge engineering handbook, Second edition: Seismic design, CRC Press: 2014 .

[29] Y. H. Liao. Research on ultra-low cycle fatigue properties and fracture mechanism of steel bridge welded joint. Master's Thesis, Zhejiang University, Hangzhou, China, 2018. (In Chinese).

[30] S. Yamada, Y. Jiao, H. Narihara. Plastic deformation capacity of steel beam-to-column connection under long-duration earthquake. International Journal of High-Rise Buildings, 2014, 3(3): 231-241.

[31] H. B. Ge, L. Kang, Y. Tsumura. Extremely Low-Cycle Fatigue Tests of Thick-Walled Steel Bridge Piers. Journal of Bridge Engineering, 2013, 18 (9): 858-870

[32] H. B. Ge, L. Kang. Ductile crack initiation and propagation in steel bridge piers subjected to random cyclic loading. Engineering Structures, 2014, 59(2):809-820. 